\title{
Automatic approach/avoidance tendencies towards food and the course of anorexia nervosa
}

Citation for published version (APA):

Neimeijer, R. A. M., de Jong, P. J., \& Roefs, A. (2015). Automatic approach/avoidance tendencies towards food and the course of anorexia nervosa. Appetite, 91, 28-34. https://doi.org/10.1016/j.appet.2015.03.018

Document status and date:

Published: 01/08/2015

DOI:

10.1016/j.appet.2015.03.018

Document Version:

Publisher's PDF, also known as Version of record

Document license:

Taverne

Please check the document version of this publication:

- A submitted manuscript is the version of the article upon submission and before peer-review. There can be important differences between the submitted version and the official published version of record.

People interested in the research are advised to contact the author for the final version of the publication, or visit the DOI to the publisher's website.

- The final author version and the galley proof are versions of the publication after peer review.

- The final published version features the final layout of the paper including the volume, issue and page numbers.

Link to publication

\footnotetext{
General rights rights.

- You may freely distribute the URL identifying the publication in the public portal. please follow below link for the End User Agreement:

www.umlib.nl/taverne-license

Take down policy

If you believe that this document breaches copyright please contact us at:

repository@maastrichtuniversity.nl

providing details and we will investigate your claim.
}

Copyright and moral rights for the publications made accessible in the public portal are retained by the authors and/or other copyright owners and it is a condition of accessing publications that users recognise and abide by the legal requirements associated with these

- Users may download and print one copy of any publication from the public portal for the purpose of private study or research.

- You may not further distribute the material or use it for any profit-making activity or commercial gain

If the publication is distributed under the terms of Article $25 \mathrm{fa}$ of the Dutch Copyright Act, indicated by the "Taverne" license above, 
Research report

\title{
Automatic approach/avoidance tendencies towards food and the course of anorexia nervosa
}

\author{
Renate A.M. Neimeijer ${ }^{\mathrm{a}, \mathrm{b}, *}$, Peter J. de Jong ${ }^{\mathrm{a}}$, Anne Roefs ${ }^{\mathrm{c}}$ \\ a Department of Clinical Psychology and Experimental Psychopathology, University of Groningen, Grote Kruisstraat 2/1, Groningen 9712 TS, The Netherlands \\ ${ }^{\mathrm{b}}$ Center for Eating Disorders, Accare, Child and Adolescent Psychiatry, Fazantenlaan 1, Smilde 9422 EZ, The Netherlands \\ ${ }^{c}$ Department of Experimental Psychology, Maastricht University, Postbus 616, Maastricht 6200 MD, The Netherlands
}

\section{A R T I C L E I N F O}

\section{Article history:}

Received 19 November 2014

Received in revised form 14 March 2015

Accepted 16 March 2015

Available online 24 March 2015

\section{Keywords:}

Anorexia nervosa

Automatic approach avoidance tendencies

Food

\begin{abstract}
A B S T R A C T
Objective: The aim of the present study was to investigate the role of automatic approach/avoidance tendencies for food in Anorexia Nervosa (AN). We used a longitudinal approach and tested whether a reduction in eating disorder symptoms is associated with enhanced approach tendencies towards food and whether approach tendencies towards food at baseline are predictive for treatment outcome after one year follow up. Method: The Affective Simon Task-manikin version (AST-manikin) was administered to measure automatic approach/avoidance tendencies towards high-caloric and low-caloric food in young AN patients. Percentage underweight and eating disorder symptoms as indexed by the EDE-Q were determined both during baseline and at one year follow up. Results: At baseline anorexia patients showed an approach tendency for low caloric food, but not for high caloric food, whereas at 1 year follow up, they have an approach tendency for both high and low caloric food. Change in approach bias was neither associated with change in underweight nor with change in eating disorder symptoms. Strength of approach/ avoidance tendencies was not predictive for percentage underweight. Discussion: Although approach tendencies increased after one year, approach tendencies were neither associated with concurrent change in eating disorder symptoms nor predictive for treatment success as indexed by EDE-Q. This implicates that, so far, there is no reason to add a method designed to directly target approach/avoidance tendencies to the conventional approach to treat patients with a method designed to influence the more deliberate processes in AN.
\end{abstract}

(c) 2015 Elsevier Ltd. All rights reserved.

\section{Introduction}

Anorexia Nervosa (AN) is characterized by extreme concerns of gaining weight despite existing underweight. Effectiveness of leading treatments for adolescents with AN such as Family Based Therapy (FBT) and Cognitive Behavioural Therapy (CBT) is however limited and relapse rates after recovery are high (see Byrne, Fursland, Allen, \& Watson, 2011; Hay, 2013; Lock et al., 2010). A key question is how to explain these limited success rates. One possible explanation for the relatively limited efficacy of those treatments might be their primary focus on conscious appraisals as the starting point of the interventions. Both CBT and FBT aim to target 'explicit' processes, by replacing dysfunctional thoughts with more effective thoughts, thus decreasing emotional distress and selfdefeating behaviour. However, dual process models emphasize that next to these more explicit, deliberate processes, also more automatic, implicit, processes exist (Gawronski \& Bodenhausen, 2006). Dual process models imply that behaviour is the consequence of

\footnotetext{
* Corresponding author.

E-mail address: r.a.m.neimeijer@rug.nl (R.A.M. Neimeijer).
}

an interplay between the reflective and the more implicit, automatic processes. In the reflective system, behaviour is guided by deliberate decision-making processes. Executive functions are needed to plan behaviour, to weigh possible consequences, and to consequently behave in an intended goal-directed manner. In the implicit (or reflexive) system, behaviour is directly activated by associative clusters in memory and this may occur spontaneously and outside of people's awareness or control. These associative clusters are formed in long-term memory through repeated experience. No executive functions or cognitive effort are needed for activating behaviour, and therefore it is assumed that this system is predictive for behaviour in situations where less cognitive resources are available (e.g., time pressure, cognitive depletion, or stress) (Strack \& Deutsch, 2004). Moreover, implicit cognitions are assumed to be critically involved in habit-like, repetitive behaviours (e.g., Strack \& Deutsch, 2004; Walsh, 2013), which are typical for AN (e.g., rigid dieting).

Clearly, one could argue that the refusal to eat in AN is a more deliberate process. Consequently, conventional treatment is used to address problematic behaviour in a top-down manner by taking the reflective system as the starting point. However, also bottomup processes might play a role in AN. Several studies provided 
evidence that implicit, automatic processes may be involved in (un)successful dieting (Roefs et al., 2011). Accordingly, studies on attentional bias show that eating disorder patients, particularly those with BN, have an attention bias for food. While in AN evidence is mixed, in BN food stimuli might elicit greater incentive saliency, prompting the desire to eat food (Brooks, Prince, Stahl, Campbell, \& Treasure, 2011). An attentional bias for food might therefore lead to increased intake (Werthmann, Jansen, \& Roefs, 2014). In addition, non-successful dieters have been found to show enhanced automatic approach tendencies towards pictorial food items (Veenstra \& de Jong, 2010). Although evidence is mixed and also some research points in the opposite direction (e.g. Fishbach \& Shah, 2006), the view that automatic processes influence actual intake is further supported by a study that showed that implicit measures were predictive for food intake in case of low cognitive resources (Friese, Hofmann, \& Wänke, 2008). Also in other areas of psychopathology a relation was found between intake and approach tendencies for the relevant substance, as for instance in alcohol (e.g. Field, Kiernan, Eastwood, \& Child, 2008). Moreover, analogue studies have shown that experimentally reducing automatic chocolateapproach tendencies also reduced participants' craving for chocolates (Kemps, Tiggemann, Martin, \& Elliott, 2013).

Whereas in disinhibited eating and addiction, heightened automatic approach tendencies may be involved, in AN, the opposite might be the crucial problem. The common approach tendencies for food might be absent in individuals with AN. In this way, AN patients are more similar to individuals with anxiety disorders, in that they too show an avoidance tendency away from disorder-relevant (threatening) stimuli (e.g., Rinck \& Becker, 2007). Avoidance of high caloric food can become a well-established habit and very resistant to change (Walsh, 2013). The successful restriction of food intake in AN patients, even under conditions that typically impair self-control might then thus be explained by assuming that automatic responses towards food are weakened or perhaps absent among AN patients. In line with such a view, recent research using an indirect approach avoidance task, provided evidence indicating that indeed the common approach bias towards high caloric food was attenuated in AN patients compared to non-symptomatic controls (Veenstra \& de Jong, 2011).

Possibly conventional treatment has a limited effect on this type of more automatic processes. It could therefore be hypothesized that treatment success is limited if these relevant automatic processes remain unaffected. In other words, limited treatment success in AN patients might be associated with a failure to enhance automatic approach tendencies towards food items. As a first step to examine whether the efficacy of the treatment of AN indeed critically depends on its success in normalizing the approach tendencies towards food, the present study tested whether approach/avoidance tendencies change over time, and examined whether the reduction in AN symptoms was associated with an increase in approach tendencies towards food. Moreover, if a lack of approach tendencies towards food indeed plays an important role in the persistence of eating disorder symptoms, relatively weak approach tendencies at baseline might be an important moderator of treatment success. Therefore, the next aim of the study was to test whether (low) approach tendencies towards food at baseline predicted (worse) treatment outcome at one-year follow up. The current study used a longitudinal design, in which approach tendencies for food and eating pathology of a large group of AN patients were measured at the moment of intake and at a fixed subsequent assessment at one-year follow up. In short, the major aim of the current study was to test whether (i) approach tendencies change between moment of intake and one year follow-up, (ii) a reduction in eating disorder symptoms is associated with enhanced approach tendencies towards food, and (iii) approach tendencies towards food at baseline are predictive for treatment outcome after one year follow up.

\section{Method}

\section{Participants}

Participants were 152 adolescents $(M$ age $=14.97, S D=1.63$, range 10-20) who were admitted between 2007 and 2012 for treatment at the Department of Eating Disorders of Accare in Smilde, and who fulfilled the DSM-IV criteria for AN ( $n=87)$, or EDNOS with characteristics of AN, as diagnosed by the child version of the Eating Disorder Examination (EDE) interview (EDE: Bryant-Waugh, Cooper, Taylor, \& Lask, 1996). The content of the child EDE is very similar to the adult EDE interview. We used the child version for all participants because we preferred one diagnostic instrument for the whole group, and to reassure that younger patients would also understand the questions. The EDNOS-group consisted of patients who met most, but not all, criteria of AN. More specifically, this group consisted of patients who had menses $(n=11)$, were underweight but less than $15 \%(n=20)$, were non fat phobic AN $(n=26)$, or had partial AN (i.e. missing 2 of the 4 criteria) $(n=7)$ (cf. Thomas, Vartanian, \& Brownell, 2009).

\section{Materials}

\section{Affective Simon Task Manikin version (AST-manikin)}

\section{Overview}

As an index of automatic approach/avoidance tendencies for food, a manikin task with food pictures was used that was based on the pictorial AST originally developed by De Houwer, Crombez, Baeyens, and Hermans (2001), and previously used in the context of eating disorder symptoms and has shown construct validity in the context of eating disorders (Veenstra \& de Jong, 2011) as well as in other kinds of psychopathology (e.g. Wiers, Rinck, Kordts, Houben, \& Strack, 2010). In order to measure the automatic reaction towards food, in a way that is relatively insensitive to strategic influences, the content of the stimuli (highfat food, low-fat food, or neutral pictures) was a task-irrelevant stimulus feature. The required response (move towards or away) was defined by the perspective of the picture: top-view or side-view. So, perspective of the picture was task-relevant for the participants and the content of the picture (i.e. food or neutral) could thus be ignored. Assignment of the required response (move towards or move away) to the taskrelevant feature (top-view/side-view) was counterbalanced over participants. The task was programmed in E-prime 1.1 (Schneider, Eschman, \& Zuccolotto, 2002) and was run on a Windows XP computer with a 22 inch CRT monitor (resolution set to 1024 by 768 pixels).

\section{Stimuli}

The selection of stimuli was based on a study on the evaluation of high and low fat food (Roefs, Herman, MacLeod, Smulders, \& Jansen, 2005) and has previously been used in studies on automatic approach tendencies in restrained eaters (Veenstra \& de Jong, 2010) and anorexia patients (Veenstra \& de Jong, 2011). Pictures are used because food pictures activate the same neural regions as tasting the actual food (Simmons, Martin, \& Barsalou, 2005). Concrete, the stimuli consisted of eight high-fat food pictures (pizza, croissant, chocolate, crisps, chips, ice-cream, brown spiced biscuit, and toast with ham and cheese), eight low-fat food pictures (strawberries, melon, grapes, popcorn, carrots, cherries, pineapple, and chicken). Five neutral stimuli were pictures of bowls and mugs. Of every stimulus, two different pictures $(380 \times 285$ pixels $)$ were constructed: one top-view and one side-view picture.

\section{Trial specification}

Each trial started with a $1000 \mathrm{~ms}$ presentation of a fixation dot. Next, a picture appeared in the middle of the screen, and a black manikin appeared above or below the picture. Participants had to move the manikin as quickly as possible, depending on instruction, towards or away from the picture by pressing the arrow buttons until the manikin 
reached the picture (approach) or the edge of the screen (avoid). During the entire task, the instruction to approach either top view or side view was the same to avoid interference effects of different instructions. In case of a correct response, the next trial started automatically. In case of an incorrect response, the next trial appeared only after the erroneous response was corrected. The task consisted of a practice block of eight trials, followed by two test blocks of 84 trials each. Trials differed in stimulus type (high caloric, low caloric, or neutral), the side from which the photograph was taken (top-view or side-view), and position of the manikin (i.e., above or below the picture). Every combination was presented equally often. Each stimulus was presented four times in each block. Trials were presented in an individually randomized order.

\section{Eating disorder examination questionnaire}

The child version of the Eating Disorder Examination Questionnaire (EDE-Q Fairburn \& Bèglin, 1994) was administered as a measure for severity of eating disorder symptoms. The EDE-Q is the questionnaire version of the Eating Disorder Examination and consists of four subscales ( $0-6$ points): restraint, eating concern, weight concern, and shape concern. The total EDE-Q score provides a global measure of the severity of eating disorder pathology. Examples of questions are: 'Have you had a strong desire to lose weight?' and 'Has thinking about shape or weight made it very difficult to concentrate on things you are interested in (for example working, following a conversation, reading)?, answered on a scale between 0 (no days) and 6 (every day). Psychometric evaluation indicates that the four subscales of the EDE-Q have excellent internal consistency and test-retest reliability (Luce \& Crowther, 1999). Also in the current sample the EDE-Q showed a high internal consistency ( 23 items, $\alpha=.93$ ). Previous normative research with adult samples ( $>18$ years) reported a mean score of 4.1 in a large group of AN patients (Brewin, Baggott, Dugard, \& Arcelus, 2014).

\section{Craving, liking, and frequency}

As explicit proxies of approach tendencies we assessed participants' craving for and liking of all food stimuli, as well as participants' frequency with which they ate the food items represented on the pictures that were used in the implicit task. To index craving we asked: 'How much do you crave this product at this moment?' Liking of food items of the AST was assessed by answering the question: "How much do you like this product?' To assess the frequency with which they ate the particular food we asked 'How frequently do you eat this product?' The questions were answered on a VAS ranging from 0 (not at all) to 100 (very much).

\section{Procedure}

Within four weeks after intake, participants carried out the ASTmanikin task. Self-report measures (VAS, EDE-Q) were administered following completion of the computer task. Finally, weight and height data of all participants were collected.

After intake, they received treatment as usual in a specialized clinic for treating eating disorders. This consisted of cognitive behavioural (group/individual) therapy varying in length, both inpatient and outpatient. Since treatment varied in time and lengthy treatment is not uncommon, a design with a fixed subsequent assessment at one-year follow up was chosen. After one year, independent of treatment status, patients were asked to participate in the follow-up assessment. Firstly, the EDE-interview was administered to verify the current diagnosis. After that, the AST-manikin and self-report measures were completed.

\section{Data reduction}

For the error-analysis of the AST-manikin, trials of which the first response was in the wrong direction were identified as errors. For the initiation time analysis, trials with errors and trials with response latencies below $200 \mathrm{~ms}$ and above $2000 \mathrm{~ms}$ were excluded from analyses.
Table 1

Group characteristics.

\begin{tabular}{|c|c|c|c|c|c|c|}
\hline & \multicolumn{2}{|c|}{ Baseline } & \multicolumn{2}{|c|}{ Follow up } & \multirow[t]{2}{*}{$t$} & \multirow[t]{2}{*}{$p$} \\
\hline & M & SD & M & SD & & \\
\hline Percentage underweight & 21.37 & 7.63 & 9.50 & 7.29 & 11.90 & $<.001$ \\
\hline EDE-Q - restraint & 3.39 & 1.69 & 1.74 & 1.34 & 8.16 & $<.001$ \\
\hline EDE-Q - eating concerns & 2.98 & 1.14 & 1.72 & 1.27 & 7.68 & $<.001$ \\
\hline EDE-Q - weight concerns & 3.84 & 1.39 & 2.43 & 1.53 & 7.60 & $<.001$ \\
\hline EDE-Q - shape concerns & 4.26 & 1.41 & 2.84 & 1.68 & 7.33 & $<.001$ \\
\hline EDE-Q - total score & 3.62 & 1.20 & 2.17 & 1.38 & 9.22 & $<.001$ \\
\hline
\end{tabular}

Note: $\mathrm{EDE}-\mathrm{Q}=$ Eating disorder examination, child version.

AST-effect scores were computed by subtracting error percentages and response latencies of approach trials from corresponding avoidance trials (cf. Rinck \& Becker, 2007). Positive AST-effects are indicative of an automatic tendency to approach rather than to avoid pictures, and negative AST-effects reflect a tendency to avoid rather than to approach pictures. Subsequently, approach bias was calculated by subtracting AST-effects of neutral pictures from AST-effect for high and low caloric food items hereby controlling for non-specific differences in approach and avoidance tendencies. Higher scores on approach bias refer to a tendency to approach high or low caloric food compared to neutral pictures, whereas lower scores refer to a tendency to avoid food.

Percentage underweight was derived from the 50th percentile of height and age. Change in approach tendencies was calculated by subtracting approach bias index at $\mathrm{T} 1$ from the index at $\mathrm{T} 2$ for both high and low caloric food. Positive scores refer to a positive change in approach tendencies (i.e. enhanced approach tendencies towards food). Change in percentage underweight and change in eating disorder symptoms was calculated by subtracting T2 scores from T1 for both percentage underweight and eating disorder symptoms. Positive scores refer to less underweight/fewer eating disorder symptoms.

\section{Results}

\section{Group characteristics}

Approximately half of the participants who were assessed at baseline also completed the assessment at 1 year follow up $(n=76)$. There were various reasons for dropping out: living too far away from the treatment centre, doing well and not wanting to be reminded, doing poorly and not feeling able to participate, and just not wanting to participate. After one year, of the 76 participants, 23 patients still met the criteria of AN or EDNOS with specific characteristics of AN. Of 5 patients the diagnosis was Bulimia Nervosa, or EDNOS (but not the 'ANlike' subtype). Forty-eight patients did not have a DSM-IV eating disorder anymore.

To test whether patients who remained in the study differed from patients who dropped out, we compared both groups at baseline by means of independent sample t-tests. Outcome of these comparisons indicated that at baseline drop-outs and completers did not differ on age, educational level, percentage underweight, scores on the EDE-Q and AST-error or AST-RT at the time they were admitted to treatment (i.e., T1). Missing data at follow up were estimated using multiple imputation, which is one of the preferred methods for dealing with (a high level of) missing data (Schafer \& Graham, 2002). Missing data were imputed 40 times with predictive mean matching, with the following predictors: percentage underweight, EDE-Q AST response latencies and errors, VAS-scores, as well as other variables outside the present study (depressive symptoms, eating disorder symptoms, body image, and selfperception) to impute as accurately as possible. Unless otherwise specified, results of the multiple imputed dataset are displayed. We report the pooled results. Overall, percentage underweight and eating disorder psychopathology were significantly decreased at one-year follow-up, see Table 1. 
Table 2

AST-Manikin: percentage errors and initiation times as a function of time and stimulus type.

\begin{tabular}{|c|c|c|c|c|c|c|}
\hline & \multicolumn{3}{|l|}{ Baseline } & \multicolumn{3}{|l|}{ Follow up } \\
\hline & $\mathrm{HC}$ & LC & Neu & $\mathrm{HC}$ & LC & Neu \\
\hline \multicolumn{7}{|l|}{ Errors } \\
\hline Approach & $18.59(13.38)$ & $14.90(9.91)$ & $20.50(11.96)$ & $13.5(7.13)$ & $13.02(6.55)$ & $18.26(10.83)$ \\
\hline Avoidance & $30.26(15.56)$ & $30.41(16.57)$ & $31.17(19.50)$ & $25.86(12.49)$ & $25.83(12.88)$ & $25.93(14.07)$ \\
\hline AST-effect & $11.66(18.27)$ & $15.51(15.36)$ & $10.67(20.67)$ & $12.34(12.59)$ & $12.81(12.51)$ & 7.67 (16.43) \\
\hline \multicolumn{7}{|l|}{ RT } \\
\hline Approach & 803 (239) & $773(186)$ & $811(192)$ & $748(130)$ & $724(118)$ & $757(121)$ \\
\hline Avoidance & 913 (208) & 889 (197) & $898(212)$ & 849 (131) & $833(106)$ & 826 (129) \\
\hline AST-effect & $109(181)$ & $116(127)$ & $88(150)$ & $100(86)$ & $109(76)$ & $69(78)$ \\
\hline
\end{tabular}

Note: Mean characteristics, with SD in parentheses; HC = High caloric food; LC = Low caloric food; NEU = neutral. RT in MS.

Do automatic approach/avoidance tendencies change from baseline to follow up?

Approach bias with error rates and response latencies were analyzed using a 2 (stimulus type: high vs low caloric food) $\times 2$ (time: $\mathrm{T} 1, \mathrm{~T} 2$ ) repeated measures analysis, see Table 2 . In the error analysis, there was a significant effect of stimulus type, $F(1,151)=6.78$, $p=.01$. Participants showed stronger approach bias towards low caloric compared to high caloric food. There was no main effect of time, $F(1,151)=1.36, p=.25$, indicating that there was no overall difference between approach bias at T2 compared to T1. There was however a borderline significant stimulus type $\times$ time interaction, $F(1,151)=3.6, p=.06$, suggesting that the effect of stimulus type differed between T1 and T2. Subsequent analyses revealed that the approach bias for HC food at T1 was significantly lower than for LC food, $t(1894)=2.48, p=.013$, whereas such difference was absent at T2, $t(225)=0.36, p=.72$. In addition, there was a nonsignificant trend that approach bias for high caloric food tended to be stronger at $\mathrm{T} 2$ than at $\mathrm{T} 1, t(999)=1.41, p=.16$, whereas the approach bias for low caloric food remained virtually identical, $t(403)=0.14, p=.89$ (see Fig. 1). To facilitate the interpretation of the current pattern of results, it was subsequently examined whether approach bias for high and low caloric food differed from zero (i.e. whether the approach/avoidance tendencies for high and low caloric food were different from neutral pictures). At T1 approach bias differed from zero only for low caloric food, $t(152)=1.55, p<.001$, whereas at T2, approach bias for both high and low caloric food differed from zero, $t(152),=1.55, p=.001$, and $t(152)=1.64, p<.001$, respectively.

In the response latency analysis, there was neither a significant main effect of stimulus, $F(1,151)=1.26, p=.26$, nor an effect of time, $F(1,151)=0.72, \mathrm{p}=.40$. Also the interaction effect did not approach significance $F(1,151)=0.5, p=.48$.

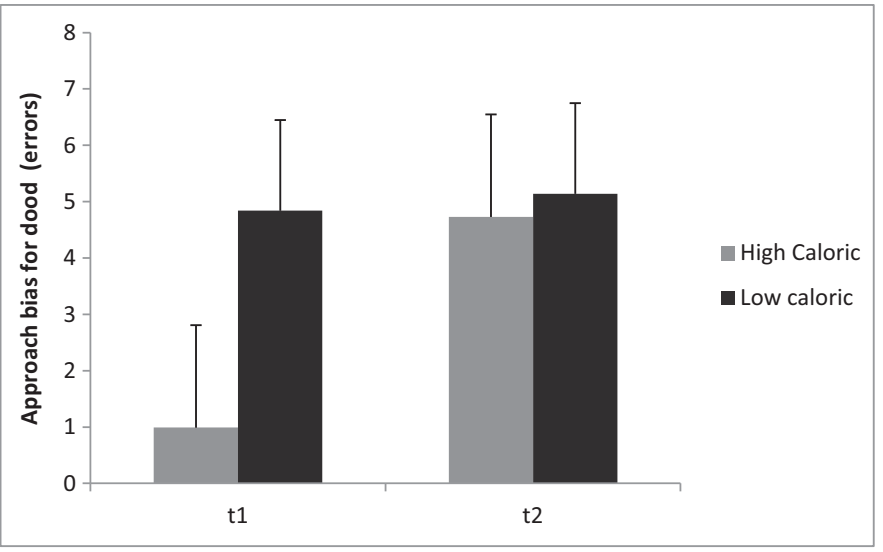

Fig. 1. Approach bias for high and low caloric food. Higher values indicate stronger approach tendencies. Error bars represent standard errors of the mean.
Since a large group still met criteria for an eating disorder at T2, an additional completers error analysis was done with diagnostic status at time 2 (recovered vs. non recovered) as between subjects variable and time and stimulus type as within subject variable. No group effect was found, neither the relevant time $\times$ group interaction was significant, $F(1,68)=.97, p=.33$ and $F(1,68)=1.57, p=.22$ respectively.

Is there a relation between change in automatic approach tendencies and change in eating disorder symptoms?

There was no relation between change in approach bias (ASTerror/AST-RT) and change in percentage underweight, nor between change in approach bias and change in eating disorder symptoms. The pattern was similar for high and low caloric food items, all $r s$ between -.11 and .09 , all $p s>.25$.

Do automatic approach tendencies at baseline have predictive value for eating disorder symptoms at one year follow up?

To determine the predictive effect of approach tendencies, the correlations between approach bias at T1 and eating disorders symptoms/percentage underweight at T2 were calculated. There was neither a significant correlation for high caloric food, nor for low caloric food. This was the case for error and response latency analyses, all $r$ s between -.05 and -.12 , all $p s>.31$.

\section{Self report measures: VASs}

Craving, liking, and frequency of eating both high and low caloric food increased significantly after one year (see Table 3). No significant correlations were found between approach bias for high and low caloric food and the self-report measures, all $r$ between -.15 and .12, all $p>$.12. Frequency of eating high caloric food at T1 was correlated with EDE-Q score at T1, $r(152)=-.208, p=.02$. Craving, liking, and frequency of eating high caloric food at T2 was associated with EDE-Qscores at T2, $r(152)=-.236, p<.01 ; r(152)=-.213, p=.01 ; r(152)=-.367$, $p<.001$. There was no significant correlation between craving and liking

Table 3

Craving, liking and frequency of high and low caloric food.

\begin{tabular}{|c|c|c|c|c|c|c|}
\hline & \multicolumn{2}{|c|}{ Baseline } & \multicolumn{2}{|c|}{ Follow up } & \multirow[t]{2}{*}{$t$} & \multirow[t]{2}{*}{$p$} \\
\hline & M & SD & M & SD & & \\
\hline \multicolumn{7}{|l|}{$\mathrm{HC}$} \\
\hline Liking & 58.12 & 26.84 & 64.25 & 17.06 & 2.71 & $<.01$ \\
\hline Craving & 24.16 & 26.42 & 36.65 & 21.58 & 5.25 & $<.001$ \\
\hline Frequency & 18.33 & 15.15 & 29.81 & 16.35 & 7.63 & $<.001$ \\
\hline \multicolumn{7}{|l|}{ LC } \\
\hline Liking & 64.30 & 18.56 & 69.89 & 12.37 & 2.71 & $<.001$ \\
\hline Craving & 31.20 & 23.76 & 45.73 & 17.30 & 6.91 & $<.001$ \\
\hline Frequency & 36.27 & 16.71 & 46.45 & 10.81 & 3.96 & $<.001$ \\
\hline
\end{tabular}

Note: $\mathrm{HC}=$ high caloric; $\mathrm{LC}=$ low caloric. 
and EDE scores at T1, $r(152)=-.0 .85, p=.33, r(152)=-.145, p=.09$, neither between change in craving and liking for high caloric food and change in EDE-Q scores, $r(152)=.109, p=.26$ and $r(152)=.110, p=.28$. Yet, there was a significant relationship between the change in frequency and change in EDE-Q $r(152)=.234, p=.01$.

\section{Discussion}

The present study investigated the course of automatic approach tendencies in AN patients. The major results can be summarized as follows: (i) Error analysis of the AST showed that anorexia patients have an approach bias for low caloric food, but not for high caloric food, at baseline, whereas at 1 year follow-up, they have an approach bias for both high and low caloric food. (ii) Change in approach bias was neither associated with change in underweight nor with change in eating disorder symptoms, and (iii) Approach tendencies towards food at baseline were not predictive of percentage underweight at 1-year follow-up.

Relationship between change in automatic approach tendencies and change in eating disorder symptoms

The first aim of the study was to verify whether approach tendencies changed during treatment and whether this was related to indices of treatment success. In line with previous research, ANpatients showed no approach tendencies for high caloric food during the baseline assessment at the time they were admitted for treatment (Veenstra \& de Jong, 2011). After one year, however, these approach tendencies increased to the level for low caloric food. The pattern of the follow up looks similar to the pattern found in healthy controls (Veenstra \& de Jong, 2011), which suggests that overall approach tendencies towards food recover back to normal after one year. It is not uncommon to find pictorial AST-effects in errors, (probably because task instruction focuses more on maximizing speed than accuracy see, e.g. Veenstra \& de Jong, 2011).

Because the used approach index (subtracting errors on neutral cues from errors on both high and low caloric food) controls for nonspecific approach tendencies, it cannot be explained by higher approach tendencies in general. It is neither plausible that learning effects (reduced interference of food as a task irrelevant feature) would have influenced the AST-effects at follow up, because the effects of food remained constant over time. In fact, if patients learned from T1 to ignore processing the task-irrelevant content of the stimuli (i.e., food itself), then AST-effects at T2 are an underestimation of the real approach tendencies towards food. Because there was no no-treatment control group, it should be acknowledged, however, that it cannot be ruled out that the found results reflect a spontaneous instead of a treatment-induced change.

The apparent recovery of approach tendencies for high caloric food was not directly associated with actual improvement of the eating disorders symptoms, as indicated by an absence of a significant correlation between change of approach tendencies and change in eating disorder symptoms. If either the implicit (AST) or the explicit measure (EDE-Q scores and percentage underweight) did not change sufficiently, this finding would be a logical consequence. However, both the explicit as well as the implicit measure improved so this provides no adequate explanation for the lack of an association. A power analysis was done, which ruled out the possibility that the study was underpowered. To reach a power of 70 with a medium effect size and an alpha of $.05,65$ participants were needed.

It seems that improvement of approach tendencies towards food is not crucial for the course of AN, and improvement in EDE scores can be attained without improvement of approach tendencies. Conversely, improvement on an implicit measure does not also imply recovery as indicated by self-report measures. This holds for at least the relatively short-term outcome, that is, one year after start of treatment. The absence of a straightforward relationship between improvement as indexed by body weight and eating disorder symptoms (EDE-Q) and improvement as indexed by increased approach tendencies towards food, may implicate that some patients have learned helpful cognitions but did not experience a change at the more implicit level. It is therefore possible that if approach tendencies remain at a low level, they have an influence on behaviour whenever food situations are encountered. Consequently, insufficiently increased approach tendencies would then heighten the risk of relapse. An important next step would thus be to find out whether patients in whom EDE-Q scores, but not approach tendencies towards food, changed in a favorable way, are at a relatively high risk for relapse. Germane to this, a recent study in the context of speech anxiety showed that the strength of residual negative automatic associations with speaking in public after successful treatment had predictive value for the return of fear (Vasey, Harbaugh, Buffington, Jones, \& Fazio, 2012). In analogy, absence of automatic approach tendencies towards food might be associated with a higher chance of a return of eating disorder symptoms.

Although treatment did not focus directly on changing automatic processes, the findings support the possibility that treatment does have an effect on approach tendencies, since there was no approach bias for high caloric food at T1, whereas there was at T2. The suggestion that treatments that focus on the more deliberate processes can be in itself also responsible for changing automatic processes, is in line with the idea that automatic processes may develop through the acquisition of new information that changes higher order beliefs, which in turn modify functionally-related lower order automatic processes (Mansell, 2000). Accordingly, although automatic processes can operate without conscious control, voluntary processes can be responsible for changes in automatic processes. However, no final conclusions can be drawn at this point since it was ethically unacceptable to include a waitlist/no treatment control condition in this group of under aged patients with a severe psychiatric disorder.

Even though results suggest that change in approach tendencies is not crucial for (short term) treatment success, it could well be that patients could benefit from an intervention that aims to directly influence individual's approach/avoidance tendencies. Supporting the view that these approach tendencies can have a causal influence on actual behaviour, a training study of approach bias towards alcohol in problem drinkers revealed that a trained decrease in automatic approach tendencies towards alcohol was associated with lower alcohol consumption (Wiers et al., 2010). Perhaps, then, AN patients could benefit from a training designed to increase (instead of to decrease) approach tendencies towards food items.

\section{The predictive value of automatic approach tendencies for eating disorder symptoms at follow up}

The next aim of the study was to determine the predictive value of approach tendencies for food on future eating disorder symptoms. Results indicated that approach tendencies at baseline were not predictive of the AN eating disorder symptoms at one year follow up. This finding supports the conventional approach to treat patients with a method designed to influence the more deliberate processes in AN. Based on the outcomes of this study, there is no direct reason to add a method to the treatment that directly targets the automatic approach/avoidance tendencies. However, it might still be that specifically for the group of AN patients with lowered approach tendencies for food at intake, it requires additional interventions such as automatic approach training to reach a sustained drop in symptoms at longer-term follow up. More research is needed to test this alternative hypothesis.

The finding that the approach tendencies are not predictive for eating disorder symptoms at 1 year follow up is not in line with the hypothesis that approach bias plays a crucial role in the maintenance of eating disorder symptoms. A possible explanation for this finding might be that initially treatment focuses especially at weight restoration. In line 
with this, after one year, frequency of eating the food items was increased. Frequency of eating food was correlated with reduction of eating disorder symptoms as indexed with the EDE-Q. However, weight is not a perfect indicator of eating disorder severity after one year. One could have a BMI that fits in the normal range, but still have distorted cognitions and low approach tendencies and, therefore, still be at high risk for relapse. Even though patients improved significantly on EDE scores, compared with adolescents with no history of an eating disorder, the scores at follow up were still high, (i.e. 1-2 sd above the mean; Watkins, Frampton, Lask, \& Bryant-Waugh, 2005). This might imply that the improvement, though statistically significant, was not yet sufficient from a clinical perspective. In line with this, a study on wanting and liking in AN patients showed that weight-restored, but not fully recovered patients showed less implicit wanting for high caloric food compared to healthy controls (Cowdrey, Finlayson, \& Park, 2013).

The outcomes of the longitudinal analyses should be interpreted with care, since the present study suffered from a substantial amount of dropout. However, we multiple imputed the missing data and completers did not differ at intake from patients who dropped out. Furthermore, there was no difference in completers analysis and analysis with imputed data. High drop-out rates are not uncommon in large clinical samples, especially not in disorders accompanying with severe physical health problems. This study provides still unique insight in cognitive processes in a large clinical sample. To gain more insight in how approach tendencies develop over time, it is crucial to have a follow up longer than one year. Many patients still met criteria for an eating disorder after one year follow up and received treatment within the one-year interval. A one year follow up was chosen instead of a pre post treatment design, thereby controlling for time. However, a limitation of this design is that after one year follow up, the treatment status varied. Approximately half the sample still met criteria for an eating disorder. However, results showed that there was no difference in approach bias between patients who were recovered and patients who still met criteria for AN. Although not meeting DSM-IV criteria for Anorexia Nervosa or Eating Disorder not otherwise specified (with specific characteris- tics of AN) anymore, they still showed high EDE-Q scores, comparable with the patient group. This strengthens the idea that a longer follow up period is needed.

\section{Implicit and explicit measures}

Although behavioural approach tendencies and the self-report proxies (craving, liking, and frequency of eating high and low caloric food-items) both seem to increase after one year follow up, there was no significant correlation between the more implicit and explicit measures. This in line with previous research (e.g. Bosson, Swann, \& Pennebaker, 2000; Veenstra \& de Jong, 2011) and one interpretation is that both types of measures assess different components of people's motivational orientation towards food. The implicit measures may more closely reflect the more automatic processes whereas the explicit measures may more closely reflect the more deliberate processing of food. Alternatively, response bias that would only affect explicit measures but not implicit measures may also explain the lack of correlation (Roefs et al., 2011). Importantly, only the change in the (explicitly reported) frequency of eating particular food-items was associated with the change in eating disorder symptoms, suggesting that especially the reduction of avoidance behaviour is relevant in the decrease of eating disorder symptoms.

\section{Conclusion}

The present study showed that although approach tendencies in AN patients increased after one year, they were neither associated with concurrent change in eating disorder symptoms nor predictive for treatment success. This implicates that, so far, there is no reason to add a method designed to directly target approach/avoidance tendencies to the conventional approach to treat patients with a method designed to influence the more deliberate processes in AN.

\section{Appendix A}

Example of an AST-manikin trial. 


\section{References}

Bosson, J. K., Swann, W. J., \& Pennebaker, J. W. (2000). Stalking the perfect measure of implicit self-esteem: The blind men and the elephant revisited? Journal of Personality and Social Psychology, 79(4), 631-643. doi:10.1037/0022-3514.79.4.631.

Brewin, N., Baggott, J., Dugard, P., \& Arcelus, J. (2014). Clinical normative data for eating disorder examination questionnaire and eating disorder inventory for DSM-5 feeding and eating disorder classifications. A retrospective study of patients formerly diagnosed via DSM-IV. European Eating Disorders Review, 22, 299-305.

Brooks, S., Prince, A., Stahl, D., Campbell, I. C., \& Treasure, J. (2011). A systematic review and meta-analysis of cognitive bias to food stimuli in people with disordered eating behaviour. Clinical Psychology Review, 31(1), 37-51.

Bryant-Waugh, R., Cooper, P. J., Taylor, C. L., \& Lask, B. D. (1996). The use of the eating disorder examination with children. A pilot study. International Journal of Eating Disorders, 19(4), 391-397. doi:10.1002/(SICI)1098-108X(199605)19:4<391::AID -EAT6>3.0.CO;2-G.

Byrne, S. M., Fursland, A., Allen, K. L., \& Watson, H. (2011). The effectiveness of enhanced cognitive behavioural therapy for eating disorders. An open trial. Behaviour Research and Therapy, 49(4), 219-226. doi:10.1016/j.brat.2011.01.006.

Cowdrey, F. A., Finlayson, G., \& Park, R. J. (2013). Liking compared with wanting for high- and low-calorie foods in anorexia nervosa. Aberrant food reward even after weight restoration. The American Journal of Clinical Nutrition, 97(3), 463-470. doi:10.3945/ajcn.112.046011.

De Houwer, J., Crombez, G., Baeyens, F., \& Hermans, D. (2001). On the generality of the affective Simon effect. Cognition and Emotion, 15(2), 189-206. doi:10.1080/ 0269993004200051.

Fairburn, C. G., \& Bèglin, S. J. (1994). Assessment of eating disorders. Interview or self-report questionnaire? International Journal of Eating Disorders, 16(4), 363-370.

Field, M., Kiernan, A., Eastwood, B., \& Child, R. (2008). Rapid approach responses to alcohol cues in heavy drinkers. Journal of Behavior Therapy and Experimental Psychiatry, 39(3), 209-218. doi:10.1016/j.jbtep.2007.06.001.

Fishbach, A., \& Shah, J. Y. (2006). Self-control in action. Implicit dispositions toward goals and away from temptations. Journal of Personality and Social Psychology, 90(5), 820-832. doi:10.1037/0022-3514.90.5.820.

Friese, M., Hofmann, W., \& Wänke, M. (2008). When impulses take over. Moderated predictive validity of explicit and implicit attitude measures in predicting food choice and consumption behaviour. British Journal of Social Psychology, 47(3), 397-419. doi:10.1348/014466607X241540.

Gawronski, B., \& Bodenhausen, G. V. (2006). Associative and propositional processes in evaluation. An integrative review of implicit and explicit attitude change. Psychological Bulletin, 132(5), 692-731. doi:10.1037/0033-2909.132.5.692.

Hay, P. (2013). A systematic review of evidence for psychological treatments in eating disorders. 2005-2012. International Journal of Eating Disorders, 46(5), 462-469.

Kemps, E., Tiggemann, M., Martin, R., \& Elliott, M. (2013). Implicit approach-avoidance associations for craved food cues. Journal of Experimental Psychology. Applied, 19(1), 30.

Lock, J., Le Grange, D., Agras, W. S., Moye, A., Bryson, S. W., \& Jo, B. (2010). Randomized clinical trial comparing family-based treatment with adolescent-focused individual therapy for adolescents with anorexia nervosa. Archives of General Psychiatry, 67(10), 1025-1032.
Luce, K. H., \& Crowther, J. H. (1999). The reliability of the Eating Disorder Examination - Self-Report Questionnaire Version (EDE-Q). International Journal of Eating Disorders, 25(3), 349-351. doi:10.1002/(SICI)1098-108X(199904)25:3<349::AID -EAT15>3.0.CO;2-M.

Mansell, W. (2000). Conscious appraisal and the modification of automatic processes in anxiety. Behavioural and Cognitive Psychotherapy, 28(2), 99-120. doi:10.1017| S1352465800213131.

Rinck, M., \& Becker, E. S. (2007). Approach and avoidance in fear of spiders. Journal of Behavior Therapy and Experimental Psychiatry, 38(2), 105-120. doi:10.1016/ j.jbtep.2006.10.001.

Roefs, A., Herman, C. P., MacLeod, C. M., Smulders, F. T. Y., \& Jansen, A. (2005). At first sight. How do restrained eaters evaluate high-fat palatable foods? Appetite, 44(1), 103-114

Roefs, A., Huijding, J., Smulders, F. T. Y., MacLeod, C. M., de Jong, P. J., Wiers, R. W. et al. (2011). Implicit measures of association in psychopathology research. Psychological Bulletin, 137(1), 149-193.

Schafer, J. L., \& Graham, J. W. (2002). Missing data. Our view of the state of the art. Psychological Methods, 7(2), 147-177. doi:10.1037/1082-989X.7.2.147.

Schneider, W., Eschman, A., \& Zuccolotto, A. (2002). E-prime reference guide. Pittsburgh, PA: Psychology Software Tools.

Simmons, W. K., Martin, A., \& Barsalou, L. W. (2005). Pictures of appetizing foods activate gustatory cortices for taste and reward. Cerebral Cortex, 15(10), 16021608.

Strack, F., \& Deutsch, R. (2004). Reflective and impulsive determinants of social behavior. Personality and Social Psychology Review, 8(3), 220-247.

Thomas, J. J., Vartanian, L. R., \& Brownell, K. D. (2009). The relationship between eating disorder not otherwise specified (EDNOS) and officially recognized eating disorders. Meta-analysis and implications for DSM. Psychological Bulletin, 135(3), 407-433. doi:10.1037/a0015326.

Vasey, M. W., Harbaugh, C. N., Buffington, A. G., Jones, C. R., \& Fazio, R. H. (2012). Predicting return of fear following exposure therapy with an implicit measure of attitudes. Behaviour Research and Therapy, 50(12), 767-774. doi:10.1016 j.brat.2012.08.007.

Veenstra, E. M., \& de Jong, P. J. (2010). Restrained eaters show enhanced automatic approach tendencies towards food. Appetite, 55, 30-36. doi:10.1016/ j.appet.2010.03.007.

Veenstra, E. M., \& de Jong, P. J. (2011). Reduced automatic motivational orientation towards food in restricting anorexia nervosa. Journal of Abnormal Psychology, 120(3), 708-718. doi:10.1037/a0023926.

Walsh, B. T. (2013). The enigmatic persistence of anorexia nervosa. The American Journal of Psychiatry, 170(5), 477-484. doi:10.1176/appi.ajp.2012.12081074.

Watkins, B., Frampton, I., Lask, B., \& Bryant-Waugh, R. (2005). Reliability and validity of the child version of the eating disorder examination. A preliminary investigation. International Journal of Eating Disorders, 38(2), 183-187.

Werthmann, J., Jansen, A., \& Roefs, A. (2014). Worry or craving? A selective review of evidence for food-related attention biases in obese individuals, eating-disorder patients, restrained eaters and healthy samples. The Proceedings of the Nutrition Society, 14, 1-16.

Wiers, R. W., Rinck, M., Kordts, R., Houben, K., \& Strack, F. (2010). Retraining automatic action-tendencies to approach alcohol in hazardous drinkers. Addiction (Abingdon, England), 105(2), 279-287. doi:10.1111/j.1360-0443.2009.02775. 